\title{
Erratum to: Diagnostic and prognostic value of sCD14-ST-presepsin for patients admitted to hospital intensive care unit (ICU)
}

Matej Godnic · David Stubljar · Miha Skvarc · Tomislav Jukic

Published online: 27 May 2015

(C) Springer-Verlag Wien 2015

In the published article, the name of the author David Stubjar is not given correct. The correct name is:

David Stubljar

The online version of the original article can be found under doi:10.1007/s00508-015-0719-5

D. Stubljar $(\bowtie) \cdot$ M. Skvarc

Faculty of Medicine, Institute of Microbiology and Immunology,

University of Ljubljana,

Zaloska 4,

Ljubljana, Slovenia

e-mail:d.stubljar@gmail.com

M. Godnic

Novo mesto General Hospital,

Novo mesto, Slovenia

T. Jukic

Medical faculty of Osijek,

Osijek, Croatia 